\title{
Del conflicto a la mediación, un recorrido por la evolución de la política y su ciencia
}

\author{
Jaime FERRI DURÁ \\ Universidad Complutense de Madrid \\ ferri@cps.ucm.es
}

Recibido: 04/06/2012

Aceptado: $13 / 11 / 2012$

\begin{abstract}
Resumen
En el ensayo elaborado se observa y explica, sobre todo para los menos acostumbrados a recorrer los caminos trazados por la Ciencia política, diversas interrelaciones entre los conceptos que se refieren a la conexión entre vida en común, convivencia humana, con conflicto y política, intentando comprender cómo y por qué sucede, para así evaluar hasta qué punto la respuesta que ofrece la política tiene vigencia, y hasta qué punto la técnica de la mediación es una alternativa a las instituciones más tradicionales, que surgieron para enfrentar el conflicto y la violencia, trazando diferentes itinerarios a través de la evolución de algunas ideas muy significativas del pensamiento; para lo que se citarán, en su caso, a diversos autores bien reconocidos, mostrando, a la vez, cómo determinados hechos contrastados exponen algunas de las causas que provocan la situación -trama- analizada. Considerando que la desacreditada política es quien procura la mediación, que también ha de ponerse en marcha con decisiones políticas. Los recorridos que se realizan, sobre todo al principio, son a través de la evolución del pensamiento y de las instituciones políticas y su finalidad es mostrar que los autores y las estructuras vistas, habitualmente conocidos al observar otras cuestiones, también se ocupan de las preguntas a las que este ensayo se refiere. Al fin se trata, en general, de determinados clásicos que pueden ser analizados desde perspectivas diversas y a los que siempre conviene volver a visitar.
\end{abstract}

Palabras clave: conflicto, violencia, política, negociación, instituciones, estado, mediación, procesos de paz

\section{Conflict, violence, politics, negotiation, institutions, government, mediation, peace processes}

\begin{abstract}
In the essay seeks to elaborate and explain observed, especially for those less accustomed to walk the paths of political science, various relationships between the concepts that refer to the connection between common life, human relations, with conflict and political trying to understand how and why it happens, in order to assess to what extent the response that provides policy is effective, and to what extent the art of mediation is an alternative to more traditional institutions that emerged to deal with conflict and violence, tracing different routes through the development of some very significant of thought to what will be cited, where appropriate, to various well known authors, showing, at a time, how certain hard evidence presents some of the causes the situation-frame-analyzed. Whereas the discredited policy is the one who seeks mediation, which must also be implemented with political decisions. The tours that take place, especially at first, is through the evolution of thought and of political institutions and their purpose is to show that the authors and the structures seen, usual-
\end{abstract}


ly known by looking at other issues, also address questions to which this test is concerned. At last it is generally of certain classics that can be analyzed from different perspectives and it is always necessary to revisit.

Keywords: conflict, violence, politics, negotiation, institutions, government, mediation, peace processes.

\section{Referencia normalizada}

Ferri Durá, J. (2013). "Del conflicto a la mediación, un recorrido por la evolución de la política y su ciencia”. Política y Sociedad, Vol.50 núm. 1: páginas. 13-38

Sumario: Introducción. 1.Conflicto y política. 2.Instituciones frente al conflicto. 3.La violencia. 4.Un giro para los conflictos. 5.El conflicto como oportunidad y la mediación para encontrarla. Procesos de paz. 6.Referencias bibliográficas

\section{Introducción}

El conflicto ocupa una posición central en la política y ambos conceptos parecen surgir y evolucionar al tiempo, pues "Allí donde hay política, descubrimos conflictos, y las distintas formas en que los seres humanos enfrentan dichos conflictos." (Dahl, 1965: 22). Sin pretender encontrar aquí un sentido extraordinario al término conflicto, se entiende que es lo que indica el diccionario de la Academia (D.R.A.E. $)^{1}$ en sus primeras acepciones: combate, lucha, pelea; enfrentamiento armado; apuro, situación desgraciada y de difícil salida; problema, cuestión, materia de discusión. A ellas nos referimos en este ensayo. Tampoco es preciso detenerse, por ahora, en saber qué es primero: ¿el conflicto?, ¿la política?, ¿el hecho de asociarse?, ¿'la autoridad? Lo que parece ineludible es que allí donde hay seres humanos que tienen asuntos en común, normalmente hay conflicto; y cuando los resuelven pacíficamente, es porque emplean la política. Pero sí resultará oportuno observar cómo y de qué manera se desarrolla la trama presentada.

En la más remota antigüedad ya podemos encontrar explicaciones, retrocediendo desde la cita de R. Dahl (1915) hasta la mitología clásica, en un extenso recorrido que también pretende expresar la omnipresencia y la persistencia de la política; y para constatarlo se puede atender al relato que Platón (428 a. C. - 327 a.C.) hace en Protágoras: “..., los hombres vivían al principio dispersos y no había ciudades, siendo, así, aniquilados por las fieras, al ser en todo más débiles que ellas. El arte que profesaban constituía un medio, adecuado para alimentarse, pero insuficiente para la guerra contra las fieras, porque aún no poseían ciencia política...buscaron la forma de reunirse y salvarse construyendo ciudades, pero, una vez reunidos, se ultrajaban entre sí por no poseer política, de modo que, al dispersarse de nuevo, perecían. Entonces Zeus, temiendo que nuestra especie quedase exterminada por completo, envió a Hermes para que llevase a los hombres el sentido moral y la

\footnotetext{
${ }^{1}$ Ver http://www.rae.es/rae.html
} 
justicia, a fin de que rigiesen en las ciudades la armonía y los lazos comunes de amistad. Preguntó, entonces, Hermes a Zeus la forma de repartir la justicia y el sentido moral entre los hombres: " ¿Las distribuyo como fueron distribuidos los demás conocimientos? Pues están repartidos así: con un solo hombre que domine la medicina, basta para tratar a muchos, legos en la materia; y lo mismo ocurre con los demás profesionales. ¿Reparto así la justicia y el sentido moral entre los hombres, o bien las distribuyo entre todos ?». «Entre todos, respondió Zeus; y que todos participen de ellas; porque si participan de ellas sólo unos pocos, como ocurre con las demás ciencias, jamás habrá ciudades. Además, establecerás en mi nombre esta ley: que todo aquél que sea incapaz de participar del honor y la justicia sea eliminado como una enfermedad de la ciudad»” (Platón, [1985: 322b-e]).

El relato merece ser examinado pues, además de los elementos que aquí más directamente interesan, contiene otros asimismo muy sugerentes y aleccionadores; aunque no podemos reparar en todos ellos. Obsérvese, con todo, que es uno de los primeros alegatos a favor de la democracia ya que, si todos poseemos, como exige Zeus, esa combinación de sentido moral y justicia, lo que parece ser un contenido esencial de la política en las palabras del texto, todos podemos y debemos participar en el gobierno de la ciudad, del estado. Hecho que puede ocurrir cuando, por ejemplo, en los sistemas políticos democráticos actuales, manifestamos nuestras preferencias en elecciones libres, en principio regidas por el lema: una persona un voto. Aunque los necesarios sistemas electorales, establecidos para contabilizar las determinaciones de un número significativo de personas, al realizar el escrutinio de los votos, pueden hacer que las preferencias de los que, en su caso, viven en algunos distritos o circunscripciones tengan un valor mayor que las de los que viven en otros; ya que es muy difícil que la misma cantidad de población resida en cada distrito o circunscripción. Por lo que el lema una persona un voto, casi siempre deja de cumplirse cuando el número de personas se eleva y distribuye desigualmente en el territorio. Y por tanto hay cierta tergiversación de dicho eslogan, pues cualquier sistema electoral beneficia más a unos que a otros; cuando de lo que se trata es de que todos participen de manera equitativa. Presupuesto, el de la igualdad a la hora de mostrar las preferencias, consustancial a la democracia que, como se muestra, resulta difícil de cumplir. Así, el ejemplo más sencillo ya puede poner en cuestión el punto de partida, y el caso expuesto sirve como una primera prueba de las complejidades, contradicciones, paradojas, en las que nos adentramos que, en lo posible, procuraremos mostrar y esclarecer.

Pero, por ahora, del texto de Platón, interesa destacar que la política es una actividad universal siempre presente, necesaria para contener los conflictos existentes en todas partes y en todo tiempo, o al menos desde que fundamos ciudades, vivimos en sociedad; a lo que estamos determinados biológicamente para sobrevivir ${ }^{2 .}$ De

${ }^{2}$ Como ejemplo extremo cabe considerar que no puede concebirse la supervivencia de un niño en sus primeros meses sin que algún adulto le alimente y le cuide. Y la misma 
hecho, hay quienes piensan que el conflicto es la fuente de la vida, pero tampoco corresponde aquí seguir el rumbo de analizar qué elementos y con qué composición se originan las condiciones que dan lugar al estado de actividad de los seres orgánicos, definición de vida según el D.R.A.E. Lo que sí nos interesa resaltar es que, de acuerdo con las explicaciones de Platón y de Dahl, en el mismo intento de buscar salida al conflicto se genera la política que, ante todo, aspira a que las consecuencias de aquel no sean trágicas, a que se resuelvan sin violencia. La política, de esa forma, superaría la violencia, la coacción, la imposición, que pueden ser consideradas como prepolítica, de acuerdo con A. Cortina $\left(2004^{3}\right)$.

Si bien, para muchos puede ocurrir que, en esos procesos, la misma política se contagie de la violencia que pretende limitar, aunque sólo sea por estar tan próximas. Así se entiende que la política, con frecuencia, adquiera una connotación tan negativa; ya que resulta evidente que la violencia es nefasta para las personas. Por lo que así se puede comprender que, en general, la gente de bien no entienda que la política también pueda ser una dedicación noble, admirable, como asimismo se pretende; al contrario, creen que está rodeada de un halo de malévola sospecha. Entre otras razones, sin entrar en el delicado tema de la corrupción ${ }^{4}$, porque el conflicto, del modo que habitualmente es percibido, también es nefasto, muy negativo, pues desencadena enfrentamientos y violencia. Además, la política también se asimila al poder, y tampoco este último tiene buen nombre, particularmente, para quien no lo tiene; y casi siempre están mal vistos, política y poder, en las consideraciones más tópicas y convencionales que son a las que ahora se alude. Aquellas que, en general, confunden el conflicto con la política, la violencia con el poder; de modo similar a como se confunde el mensaje con quien lo transmite: el mensajero. Con esa visión tan negativa pero interesada, de ser cierto su planteamiento, los pocos que se dedicarían a la política, pues pocos querrían estar entre sus filas, no tendrían competencia, ni oposición, y podrían operar sin resistencia; por lo que sus decisiones siempre serían acatadas, lo que les supondría una situación muy ventajosa. De esa forma, esos pocos políticos que, en general afirman estar ahí para sacrificarse por alguna alta causa, también procuran mantener y alentar esas negativas visiones que tan convenientes son para ellos, pues así sólo ellos deciden, sin tener que rendir cuentas. Repárese que de esa manera es como se conducen las dictaduras,

supervivencia de la especie humana también depende de que sigamos manteniendo relaciones.

${ }^{3}$ Que textualmente afirma: "En política, según la tradición aristotélica que más tarde prolonga el republicanismo, ante todo (los ciudadanos deliberan) sobre lo justo y lo injusto. $\mathrm{Y}$ en esto consiste esencialmente la política, en que los ciudadanos deliberen sobre lo justo y los injusto, porque lo otro, la coacción, la violencia y la imposición no son todavía política, sino prepolítica”, en Cortina, A. (2004), Democracia deliberativa, El País, 24 de agosto.

${ }^{4}$ Sobre su prevención, puede verse: Ferri Durá, J. (Coord.), Román Marugán, P., Cotarelo, R., y Noguera, T. (2006), Ética pública y buen gobierno, Instituto Madrileño de Administración Pública. 
donde los autócratas, con sus adláteres, son quienes mejor promocionan esa interesada forma de concebir la trama en la que la supuesta sucia política sólo es para ellos $^{5}$. Sobre esas visiones tan desfavorables para la política y el poder, profundamente arraigadas en amplias esferas de la sociedad, se irán operando algunos cambios a medida que otras concepciones más abiertas y cabales consiguen restablecerse, como se va a observar.

Pero, volviendo sobre nuestros primeros pasos, de la misma forma que se ha citado a la mitología griega con el relato de Platón para establecer un origen y una explicación sobre la política, que aún llega hasta nuestros días, también se podría aludir al conflicto, generalmente más conocido y próximo, que enfrenta a los primeros padres del universo, surgidos directamente de las manos de Dios en el libro sagrado: Adán y Eva enfrentados en el paraíso terrenal, cuando Adán es tentado por su compañera y no desea comer del fruto del árbol de la ciencia del bien y del mal. Sin embargo, Eva deseaba que él comiera del fruto prohibido (Génesis 3, 1-6). Pero la narración bíblica que expone el primer conflicto de carácter no violento tiene un contenido demasiado misógino (otro conflicto intemporal, pero a la vez muy actual): la primera mujer es la culpable del pecado original que para siempre arrastra y condena a toda la humanidad fuera del paraíso. Por lo que ya no debiera considerarse un buen ejemplo, aparte de que al estar tomado de la Biblia, de su libro fundacional, el Génesis, y de tener por ello una obvia finalidad religiosa, se desvía de la explicación laica que la Ciencia política requiere; y más a medida que así logra hacerse autónoma para explicar los fenómenos por los que se interesa (Sartori, 1999: 238). De no ser así, de igual manera se podría recurrir, como ejemplo de conflicto violento, nada menos que al primer parricidio entre hermanos, precisamente entre los hijos de la primera pareja, la muerte de Abel a manos Caín; también en el Antiguo testamento y en el mismo libro, el Génesis $(4,8)$, sobre el origen del mundo.

En el ensayo que aquí se elabora se procura observar y explicar, sobre todo para los menos acostumbrados a recorrer los caminos seguidos por la Ciencia política, diversas interrelaciones entre los conceptos ya mencionados y algunos otros más recientes, trazando diferentes itinerarios a través de la evolución de determinadas ideas muy significativas del pensamiento político; para lo que se citarán, en su caso, a algunos autores bien reconocidos, mostrando, a la vez, cómo ciertos hechos contrastados exponen algunas de las causas que provocan la situación -tramaanalizada que conecta vida en común, convivencia humana, con conflicto y política, intentando comprender cómo y por qué sucede, para así evaluar hasta qué punto la respuesta que ofrece la política sigue vigente, y hasta qué punto la técnica de la mediación es una alternativa, o no, a la política más tradicional, institucional, burocratizada, que surge en un momento determinado que también se examina. Se trata de recorrer diferentes trayectos que los conflictos transitan, en general en términos

\footnotetext{
${ }^{5}$ Puede recordarse, como ejemplo, la frase atribuida al general Franco para contestar a la cuestión que le planteó uno de sus ministros: "Haga como yo, no se meta en política”.
} 
abstractos, viendo cómo las respuestas -políticas-que obtienen no logran cerrar, digámoslo así, todas sus vertientes; por lo que se hace preciso buscar salidas y, entre ellas, la mediación, como fruto indirecto de una larga serie de cambios desarrollados después de las dos guerras mundiales. Aunque éste hecho no significa que la política, en sentido amplio, deba ser más desacreditada aún; al fin la mediación también es política y, sin duda, ha de ponerse en marcha con decisiones políticas. Los recorridos que se realizan, sobre todo al principio, son a través de la evolución del pensamiento y de las instituciones políticas y su principal finalidad es mostrar que los autores y las estructuras vistas, habitualmente conocidos al observar otras cuestiones, también se ocupan de las preguntas a las que este ensayo se refiere. Al fin se trata, en general, de determinados clásicos que pueden ser analizados desde perspectivas diversas y a los que siempre conviene volver a visitar.

\section{Conflicto y política}

Siguiendo con la indagación, apenas iniciada, ya se puede conjeturar que la política, prevista en principio para reducir el conflicto, también puede desencadenar más conflicto, por paradójico que a priori pueda parecer. Una explicación ya puede observarse en Maquiavelo (1469-1527), cuando afirma: "En cualquier ciudad hay dos inclinaciones diversas, una de las cuales proviene de que el pueblo desea no ser dominado ni oprimido por los grandes, y la otra que los grandes desean dominar y oprimir al pueblo" ( [1970]: 5) ${ }^{6}$, y más adelante, él mismo lo atribuye a: "La tendencia a dominar (que) es propia de todo individuo o, en todo caso, del individuo que vive en sociedad. La motivación podría centrarse en la escasez. Dado que los bienes materiales deseables acostumbran a ser escasos, el elemento dominante puede orientar la producción, distribución, intercambio y consumo en beneficio propio". Lo que supone un acercamiento, por su incidencia en la escasez de recursos, a la razón de ser que los economistas esgrimen para su causa que, hoy día, más de quinientos años después, se mantiene con conceptos y términos muy similares; siendo retomada en el ámbito de la política: "El origen de los conflictos se sitúa en la existencia de diferencias sociales, que se convierten a menudo en desigualdades" (J.M. Vallès, 200: 19), y continua el autor: "Quienes creen disfrutar de situaciones más ventajosas se esfuerzan generalmente por asegurarlas y luchan por no perderlas. Por su parte, quienes se sienten más perjudicados aspiran por hacer realidad sus expectativas de mejora. $\mathrm{O}$ simplemente pugnan por sobrevivir en su misma condición de inferioridad, sin ser totalmente marginados o aniquilados. Junto a unos y otros, también los hay que se empeñan en mantener o modificar las condiciones existentes, movidos por principios y valores y no por lo que personalmente se

${ }^{6}$ Tomo la referencia de Scheherezade Pinilla, en Las ciudades intermitentes: el heroísmo de los muchos en Balzac y Galdós, Tesis doctoral, 2010, edición privada, p. 51. 
juegan en el asunto". Concluyendo J.M. Vallès (1940): "Esta combinación de resistencias, expectativas, reivindicaciones y proyectos genera sentimientos de incertidumbre, de incomodidad o de peligro". Y es en ese marco tenso e inestable, conflictivo, donde aparece la política; así, esta sería una respuesta colectiva al ineludible desacuerdo. Una respuesta que pretende regular la tensión social que generan múltiples conflictos; y el civilizado instrumento que la política utiliza es la adopción de decisiones, por parte de los grandes -de acuerdo con las palabras de Maquiavelo-, que pretenden obligar a todos los miembros de la comunidad, a todos los que a su vez originan conflictos por causas heterogéneas. Lo que sucede es que cualquier decisión, por su contenido, o por la obligatoriedad, o por el mero hecho de producirse, también puede desencadenar un nuevo conflicto. Pues no todos y siempre quedan satisfechos con las decisiones políticas que adoptan los grandes.

Por lo que termina generándose, tanto en la explicación de Maquiavelo como en la que se hace en la actualidad, una especie de bucle, un círculo vicioso, del que parece que no se puede salir: conflicto-política-conflicto-política-....R. Dahl lo expresa con claridad: "De hecho, cuando los seres humanos viven juntos en asociaciones y crean reglas, autoridades o gobiernos para que se ocupen de (los)...conflictos, los mismos intentos de gobernar contribuyen a su vez a generar conflictos.” (1965: 22). Se trataría de una especie de condena que puede recordar a la que se narra en el mito de Sísifo, volviendo a la mitología helénica; según este relato, los dioses condenaron a Sísifo, por su extremada inteligencia y astucia, a empujar eternamente una roca hasta lo alto de una colina, desde donde la piedra volvía a caer por su propio peso. Pensaron, con cierta razón, que no hay castigo más terrible que el trabajo inútil y sin esperanza. Y de la misma forma, cada vez que se busca una salida al conflicto, con el establecimiento de una determinada política, se puede estar originando otro conflicto. Y, como le sucede a Sísifo ${ }^{7}$, parece que estamos indefinidamente condenados a vivir conflictivamente. La política así no consigue desembarazarnos definitivamente de este estado de permanente conflicto, quizá por eso también se encuentre tan mal conceptuada por los bien pensantes. En todo caso, la discrepancia parece ineludible, pues siempre puede haber alguna persona insatisfecha, y por tanto predispuesta a crear nuevos enfrentamientos; al margen de que la decisión política adoptada, si la hay, sea de una u otra naturaleza. Aspecto que no es baladí y que, sin ánimo de profundizar ahora en ello, indirectamente pone de manifiesto otra de las paradojas intrínsecas a la política; pues a pesar de sus buenas intenciones, mitigar el conflicto pretendiendo con ello hacer el bien, al tiempo puede hacer el mal, traer otros males. Aunque dichos males no necesa-

${ }^{7}$ Ver, A. Camus, en El mito de Sísifo. Ensayo sobre el absurdo (numerosas ediciones, recientemente en español, 2010, Losada, Buenos Aires), donde, en particular, se plantea la cuestión del suicidio ante el absurdo de la vida; y hacia el final de la obra considera que a pesar del eterno castigo hay que imaginarse a Sísifo feliz, aunque sólo sea en los instantes en que la roca ya ha alcanzado la cima y todavía no se desprende. 
riamente sean objetivos, y sólo sean vistos de ese modo por la persona (pre)dispuesta en ese sentido; lo que pone de manifiesto el aspecto subjetivo que también tiene el conflicto.

La respuesta al aparente círculo vicioso puede estar en el hecho de que "la esencia misma de la política, su naturaleza propia, su verdadero significado es que es, siempre y en cualquier parte, ambivalente”, como afirmaba M. Duverger (1970: 38), quien también recurre a la mitología, en este caso, latina pues continua diciendo: "La imagen de Jano, el dios de doble cara, es la verdadera representación del poder: expresa la realidad política más profunda. El Estado - y de una forma más general el poder político instituido en una sociedad - es siempre y en cualquier parte, a la vez el instrumento de dominación de ciertas clases sobre otras, utilizado por los primeros en su provecho y en perjuicio de los segundos, y un medio de asegurar un cierto orden social, una cierta integración de todos en la colectividad para el bien común. La proporción de uno y otro elemento es muy variable, según las épocas, las circunstancias y los países; pero los dos coexisten siempre" (pp. 38 y 39). La idea de M. Duverger (1917) también conecta con el -tópico- dictum formulado por Lord Acton (1834-1902): "El poder tiende a corromper y el poder absoluto corrompe absolutamente". Al fin, como se ha afirmado: "La historia humana es una constante práctica conflictiva. Y sin embargo, cuando intentamos entender conflictos y solucionarlos, solemos buscar las causas y consecuencias de los conflictos fuera del proceso mismo del conflicto. En realidad, el conflicto tiene su propia dinámica que no se reduce al contexto en que se genera ni se agota en la representación que nos hacemos de las causas de un conflicto" en palabras de M. Castells (en Vinyamata, 2001:7), que en adelante comprobaremos.

Si bien, aquí nos interesa reparar, antes de proseguir, en que al encontrarse tan conectados, conflicto y política, en ocasiones se pueden buscar explicaciones que pretendan soslayar la presencia del mismo conflicto, incluso de la siempre sospechosa política; lo que parece ocurrir con alguna frecuencia. Por una parte porque la política, y en concreto la Ciencia política, parece que se ha dedicado, más que a analizar y resolver los conflictos, a buscar cómo y qué hacer para que no se produzcan, a discernir sobre cómo se debe actuar para que se diluyan, para contenerlos; y así, muchos entre sus cultivadores han elaborado su reflexión politológica o para corroborar a la autoridad establecida, la que logra apaciguar el enfrentamiento, o para reforzar el poder que a priori consigue que los conflictos se superen, o aún para reconocer legitimidad al gobierno existente. Tareas a las que parece dedicado una numerosa parte del pensamiento político, hay que suponer que quizá interesado en asegurar su propia vida buena; aunque por otro lado también entre los mismos hay visiones conflictivistas.

Desde la Sociología parece que ocurre algo similar, y más en concreto con la importante corriente teórica del funcionalismo sociológico que "no ignora los procesos conflictivos, pero es evidente que lo que suele interesarle es su resolución a través de fenómenos de adaptación, evolución, negociación, y demás. Y al revés, el enfoque conflictivista (el de la teoría del conflicto o conflict theory) también está interesado en explicar situaciones de integración, pero en su caso ésta es entendida 
en términos de hegemonía, dominio, deferencia forzada, ideología, enajenación, manipulación de unas personas por otras, subordinación y otros fenómenos de parecida índole” (Giner, 1998: 140). En esquema, se puede entender que existirían dos grandes enfoques teóricos en torno al conflicto, por un lado el de quienes se inclinan por entender la vida social en términos armónicos; entre otros, desde los orígenes del pensamiento occidental, Platón, y también Aristóteles (384 a.C.-322 a.C.), aunque para este último, en particular, habría que diferenciar su teoría de la revolución que debe considerarse como una explicación particular para entender un fenómeno que no encaja con su posición general; y por otra parte, estarían quienes se inclinan por entenderla como algo esencial e inevitablemente conflictivo, así entre los clásicos, Heráclito de Éfeso (535 a. C.- 484 a.C.) ${ }^{8}$, Polibio (200 a. C.-118 a.C.), que llegan a considerarla hasta trágica. Siguiendo con la explicación que ofrece S. Giner (1934) es a partir de Maquiavelo, pero particularmente de Hobbes (1588-1651), tanto en su interpretación de la revolución inglesa, en el Behemoth, como en su tratado general sobre el poder, el Leviatán, cuando se instaura con más claridad la tradición conflictivista moderna, que tiene una primera y destacada expresión sociológica en C. Marx (1818-1883). No sólo por su visión trágica del progreso de la humanidad, sino muy específicamente por su teoría de las contradicciones internas del capitalismo, de la lucha de clases y la inevitabilidad de la revolución, que constituyen el punto de arranque de una de las corrientes más poderosas del enfoque conflictivo.

Sin juzgar ahora las razones que motivan la actuación de algunos de sus más destacados seguidores, sí cabe recordar algunas frases, más o menos conocidas, que con claridad ponen de manifiesto sus pretensiones: "La violencia es la comadrona de una sociedad vieja preñada de otra nueva", afirma el propio Marx; "No se puede hacer una tortilla sin romper los huevos", atribuida a V.I. Lenin (1870-1924); y de Mao Zedong (1893-1976) se puede mencionar: "El poder político surge del cañón de una pistola". Todo lo que contribuye a explicar que el siglo XX haya sido, por ahora, el más conflictivo, cruento, de la historia; sobre todo si atendemos a que radicalmente enfrente de la actuación de los personajes citados, y de sus numerosos seguidores, se sitúan, sin pretender dar un solo paso atrás, con un impresionante arsenal ideológico, militar y propagandístico, los defensores del orden establecido, aquellos que se erigen en patrocinadores de la armonía social, por lo general, con bastantes más medios para la batalla.

También se podría acudir a otras conocidas teorías, más o menos próximas y estructurales, para ver cómo se afronta el conflicto desde otras posiciones; como la elaborada desde la psicología profunda por S. Freud (1856-1939), quien entiende que los humanos viven atenazados entre las exigencias biológicas del ello, gobernado por el principio del placer, y las convenciones sociales regidas por el principio

${ }^{8}$ Quien afirma: "Hay que entender que el conflicto es universal y que la Justicia es una lucha. Todo se engendra en este combate por la satisfacción de las necesidades”. 
de realidad que determina la actuación del yo. Contradicción que provoca, en la sociedad y en los individuos que Freud observa y analiza, un permanente conflicto, del que la neurosis, en sus términos, la histeria, los actos fallidos y en general el malestar psicológico, son expresiones manifiestas de acuerdo con su análisis ${ }^{9}$. Incluso se puede argumentar el darwinismo social ${ }^{10}$, a pesar de su aparente menor predicamento académico actual, siguiendo con teorías explicativas del conflicto, pues para quienes lo sostienen éste es un reflejo de la lucha de las especies por la supervivencia, que se producirá siempre que haya competencia para que determinados individuos o colectivos sobrevivan; el más apto es el que sobrevive, es el seleccionado. Visión que a algunos, conservadores más bien radicales como Ch. Maurras $^{11}$, les permite argumentar en contra de la igualdad. Aunque también, siguiendo un camino opuesto, se podría considerar la cooperación, frente a la tan aludida competencia, para salir de esos u otros conflictos, pero todavía conviene esperar y no adelantar acontecimientos.

\section{Instituciones frente al conflicto}

Pues también interesa observar, antes y desde otra perspectiva, que frente a tanto conflicto, elaborado desde el pensamiento y, con frecuencia, puesto en marcha por numerosos militantes activistas, la civilización occidental en particular crea una serie de instituciones: parlamentos, tribunales, asambleas, cámaras, normas, consejos, comisiones, partidos políticos, entre otras, que son producto de la voluntad de muchos durante un largo proceso, cuyo fin no será resolver directa y definitivamente los consabidos conflictos; lo que en ocasiones resulta casi imposible -como también vamos a observar-, sino canalizarlos, someterlos a procedimientos pautados, ya que de ese modo se consigue hacerlos llevaderos, de forma que no arrastren al conjunto de la sociedad a una dinámica de permanente guerra entre todos. Será a partir de la revolución francesa y de la norteamericana, en particular, cuando se logre que esas y otras instituciones reduzcan el conflicto mediante el establecimiento de principios y pautas, como la separación de funciones y de poderes, a las que

${ }^{9}$ Entre las numerosas obras de S. Freud, quizá la más adecuada para observar lo que atrás se menciona esté en El malestar en la cultura, numerosas ediciones, recientemente en español, 2010, en Alianza, Madrid.

${ }^{10}$ Del autor que da el nombre a la teoría, Charles Darwin, puede verse su conocida obra, El origen de las especies, en castellano, Ed. Espasa-Calpe, 2008.

${ }^{11}$ Citado por Pisier, E., Duhamel, O., y Châtelet, F. (2006), Historia del pensamiento político, Tecnos, Madrid, al hablar del Estado-fuerza (en el capítulo VI) y Del Nacionalismo al racismo (apartado1). 
tanto J. Locke (1632-1704) ${ }^{12}$ como Montesquieu (1689-1755) ${ }^{13}$, junto a otros, confieren un sólido pensamiento, con el imperio de la ley, la construcción del estado de derecho, el establecimiento de garantías jurídicas en normas constitucionales; con lo que, en cierto modo, ese conjunto institucional logra enfriar los conflictos. Resolverlos definitivamente será algo quimérico.

Si bien las revoluciones citadas, y otras, para triunfar, también han de desarrollar otros enfrentamientos, conflictos, lo que repudian sus dirigentes, según suelen afirmar; contradicciones que no cesan en el terreno sobre el que nos movemos. Y será el poder judicial, a lo largo de un prolongado proceso de construcción, quien procure que los individuos, por lo general, no se tomen la justicia por su cuenta; y serán los parlamentos quienes, a pesar de las controversias y problemas, procuren evitar que los debates sobre los asuntos políticos, todos con una carga mayor o menor de conflictividad, no se diriman en cruentos enfrentamientos callejeros, aunque estos subsistan. Las instituciones, estructuras de decisión y de intermediación, con el poder que consiguen conquistar, si se consolidan, llegan a aminorar las controversias, tras una larga senda de aciertos y errores, que para nosotros tienen su arranque en la Grecia clásica y que van consiguiendo hitos importantes a través de revoluciones, como las citadas, y de otras; y sobre todo de hechos, como la previa construcción de los estados que contienen a las mencionadas instituciones. Aunque con la consolidación estatal también se producirá la emergencia, muy directamente, de los nacionalismos que en numerosas ocasiones acarrearán guerras, fracasos de la política.

Son los estados nacionales, a pesar de todo, como forma de organización política, quienes se impondrán de manera discontinua y variada, primero, en Europa, desde el Renacimiento, y, posteriormente, sobre todo en el siglo XX, en el resto del mundo; y a medida que esos estados se consolidan es como también se consigue templar los conflictos más importantes de su momento. Las condiciones mínimas que identifican a esa nueva entidad política, surgida de las ruinas del orden medieval, serán: 1) la eliminación, o al menos la importante relegación, de determinados poderes intermedios muy importantes hasta ese nuevo período, entre otros, la nobleza, el clero y en especial la jerarquía eclesiástica, así como los gremios; 2) el establecimiento de un poder central, suficientemente fuerte, frente a otros poderes de ámbito local; y 3) el ejercicio de ese poder sobre una entidad territorial delimitada, en la que se asienta una población determinada, que tiene el atributo decisivo de la sobe-

${ }^{12}$ De quien debe destacarse su obra de más repercusión, en castellano, Segundo tratado sobre el Gobierno civil: un ensayo acerca del verdadero origen, alcance y fin del Gobierno civil, con Prólogo y notas de Felipe Mellizo, en Alianza Ed., 2002.

${ }^{13}$ Quien en 1748 publica la que es considerada su obra principal, Del espíritu de las leyes, de gran impacto ya en su época, se hicieron veintidós ediciones en vida del autor; en castellano, entre otras puede verse, con introducción de E. Tierno Galván, Alianza Ed., 2003, y de C. Iglesias, El pensamiento de Montesquieu, Ed. Galaxia Gutenberg-Círculo de lectores, 2005. 
ranía como autoridad suprema e incuestionable, fuente de toda decisión, de toda norma; aspecto por el que la reflexión que realiza J. Bodino $(1529-1596)^{14}$, en particular, es muy valorada.

El proceso que lleva a la consolidación estatal exige una sólida estructura organizativa, administrativa, conformada mediante la división en diferentes ramas: Guerra -precisamente-, Hacienda, Relaciones Exteriores, Justicia, entre otras que más tarde se crearán, precisando todas ellas para su funcionamiento de burócratas profesionales. Burocracia a la que también se achaca los déficits de las instituciones, el relativo y contradictorio fracaso de la estructura estatal, sobre todo, cuando sólo se atiende a los engorrosos procedimientos que, en general, dilatan la adopción de decisiones, perjudicando en general a los más necesitados. Además el proceso aludido se ve acompañado de numerosos enfrentamientos bélicos, la contradicción consecuente que de hecho supone el fracaso de la política; en particular, entonces, a partir del Renacimiento, habrá guerras, con frecuencia, de religión, dinásticas, con reformas -como la protestante-, y la contrarreforma católica. Junto a otros acontecimientos que también, en principio, logran relegar determinados conflictos, hasta la época considerados muy importantes, para abrir otros, en una dinámica contradictoria que muy poco a poco consigue que el estado con su poder soberano se imponga en un territorio delimitado y sobre una población dada. Max Weber (1864-1920), después de observar su evolución a lo largo de algunas centurias, sintetiza una definición analítica valorando sus aspectos más destacables: -Se trata de un conjunto diferenciado de instituciones y de personal; -con un nivel importante de centralización que consigue que su poder se irradie desde el centro hasta cubrir todo el territorio; y sobre todo dotado con el monopolio de dictar normas vinculantes y con autoridad "basada en el medio de la violencia legítima (es decir, de la violencia considerada como legítima)" ([1919] 1992: 91); con lo que parece que el problema de la violencia queda solucionado, pues sólo el estado puede disponer de ella, detrayéndola de la sociedad. Pero sólo es una_pretensión, pues como bien dice la definición del mismo Weber: "Por estado debe entenderse un instituto político de actividad continuada, cuando y en la medida en que su cuadro administrativo mantenga con éxito la pretensión al monopolio legítimo de la coacción física para el mantenimiento del orden vigente" ([1922]1944: 54).

Ese modelo estatal, consolidándose de hecho sobre todo a partir de la paz de Westfalia (1648) y hasta nuestros días, no para de evolucionar, desde su compleja fundación en Europa, y de expandirse a otras áreas geográficas; en ocasiones consiguiendo los mismos objetivos, aplacar determinados conflictos. Aunque también se debe reparar en que, más o menos al tiempo, también se genera la -llamada- Socie-

${ }^{14}$ Quien plasma en 1576 las principales ideas de su posición política en un libro fundamental para la historia del pensamiento político occidental: Los seis libros de la República, Centro de Estudios Constitucionales, 1992. 
dad civil ${ }^{15}$, el heterogéneo conjunto de asociaciones, organizaciones, clubs, voluntarios y sin ánimo de lucro, que también forman parte del espacio público pero que, aquí, lo hacen escapando al control del estado, al que restan protagonismo. Si bien en determinados lugares, con la implantación de la estructura estatal, y acaso por no disponer de una Sociedad civil sólida, junto a otras causas, se desencadenan guerras internas, se dispara la violencia; véase la situación en algunos zonas de África, particularmente después de la descolonización y hasta nuestros días donde, como se verá, las negociaciones y mediaciones conducentes a procesos de paz se han empleado posteriormente.

Obsérvese que lo importante no es tanto el conflicto concreto que se trate, como que las políticas que se aplican no desencadenen la agresión de unos a otros; pues parece que lo que sí que consigue hacer la política, al menos en un principio, es reducir el riesgo de que se declaren hostilidades, que se rompan relaciones, que se entre en una espiral incontenible de violencia; en definitiva la forma estatal parece que consigue amortiguar, reducir, los conflictos. Con todas las contradicciones que su presencia también desata. K. Smitt (1888-1985) mantendrá una posición que puede hacer más visible la concepción de la política que expresa algunas de esas contradicciones; para él el concepto del estado presupone el de lo 'político', y el estado es definido como el status político de un pueblo organizado sobre un territorio delimitado. Pero para él, en su época, ese estado está entremezclado con la sociedad, hasta el punto de que lo político no admite ser definido por lo estatal; por lo que para llegar a una definición de lo político se requiere el descubrimiento y la fijación de una distinción específica, radical, a la cual sea posible referir las acciones y los motivos políticos, y esa distinción es la de 'amigo y enemigo', que determina la esencia de lo político ${ }^{16}$. Lo que parece muy elocuente. Pero que cabe interpretar como el estado de la cuestión en una determinada época de la que aún, a pesar de los intentos que vamos a observar, somos herederos. Como lo somos del legado que supone ver el conflicto con pesimismo, y a la política sólo dispuesta para el poderoso que amenaza y, a veces, utiliza la violencia.

${ }^{15}$ Reconocida por J. Locke, y más en particular por A. Fergusson (ver, Un ensayo sobre la historia de la sociedad civil, 1974, Instituto de Estudios Políticos) , por G.W.F. Hegel (ver, Principios de la filosofía del derecho o Derecho natural y ciencia política, 1999, Edhasa), A. de Tocqueville, (ver, La democracia en América, 2010, Ed. Trotta), entre otros muchos autores y obras, de la actualidad, M. Kaldor (ver, La sociedad civil global: una respuesta a la guerra, Tusquets, 2005).

${ }^{16}$ Sigo las indicaciones que J. Franzé hace en (2004), ¿Qué es la política? Tres respuestas: Aristóteles, Weber y Schmitt, Ed. La Catarata. 


\section{La violencia}

Probablemente, la violencia sea el mejor indicador de cómo los conflictos se convierten en realmente insoportables, entre otras cosas porque la contradictoria política/poder no siempre consigue imponerse; entendiendo que hablamos de violencia cuando hay "agresión gratuita y, en una u otra medida, intencionada a la integridad física de una persona que hasta ese momento vivía en paz” (J. Keane, 2000: 16). La violencia que se impone en Europa de manera patente durante las dos Guerras mundiales, de 1914 a 1918 la primera, con más de nueve millones de combatientes muertos; y entre 1939 y 1945, la segunda gran guerra, que produjo más de sesenta millones de víctimas, extendiéndose prácticamente a todos los continentes, y experimentándose por primera vez las terroríficas armas nucleares. Ante las que se levantaron, después de la victoria de unos sobre otros, instituciones internacionales para que promovieran la paz, de manera directa, la Sociedad de Naciones, tras la primera gran guerra, con pésimos resultados; posteriormente la Organización de Naciones Unidas, e incluso la Comunidad Económica Europea, hoy Unión Europea.

Aspecto crucial el de la violencia sobre el que, en general, apenas ha reflexionado la teoría política contemporánea, salvo algunas excepciones, según considera el propio J. Keane; quizá porque, siguiendo al citado autor, se quiere pensar que entre nosotros, en el civilizado orden democrático occidental, apenas hay agresiones hoy en día, se han superado, dado que se supone que están monopolizadas por el estado definido territorialmente (si bien, se ha observado que $\mathrm{M}$. Weber -referencia obligada al considerar el monopolio legítimo- de lo que habla es de pretensión) , o porque es un anatema que transgrede el principio de la sacralidad humana y sólo se produce allí dónde la vida no está tan reconocida como en el civilizado occidente. Véanse, por ejemplo, los lugares donde aún se produce el fenómeno terrorista, donde los sicarios pueden contratarse en cualquier esquina de la ciudad, donde las maras u otras formas de violencia juvenil campan imponiendo su ley, entre otros fenómenos de violencia, como la violencia machista. Pues las democracias occidentales, en su gran mayoría, parecen estar a salvo de semejantes desviaciones; aunque cualquier violencia para ser controlada también tiene que ser combatida, según se opina, acaso siguiendo la máxima latina, si vis pacem, para bellum, pues algunas de dichas democracias combaten con armas mortíferas, con policías, ejércitos, extendiendo la violencia en aras de que se respeten sus sacrosantos valores; y así acuden con sus tropas a lugares bien remotos, en tiempos recientes, primero Vietnam, después Afganistán, Irak más tarde...Reproduciéndose un nuevo ciclo de violencia, de fracaso de la política.

Entre las excepciones del pensamiento teórico que sí meditan sobre la significación e importancia de la violencia, está en un lugar destacado H. Arendt (1906-1975) quien, en concreto, sobre las relaciones entre ésta y el poder, considera que: "el poder corresponde a la esencia de todos los Gobiernos, pero no así la violencia. La violencia es, por naturaleza, instrumental; como todos los medios siempre precisa de una guía y una justificación hasta lograr el fin que persigue. Y lo que necesita justificación por algo, no puede ser la esencia de nada”. Precisando a continuación 
que: "El poder...es, como dicen, <un fin en sí mismo>. (Esto, desde luego, no es negar que los Gobiernos realicen políticas y empleen su poder para lograr objetivos prescritos. Pero la estructura del poder en sí mismo precede y sobrevive a todos los objetos, de forma que el poder, lejos de constituir los medios para un fin, es realmente la verdadera condición que permite a un grupo de personas pensar y actuar en términos de categorías medios-fin).”, y más adelante: "El poder no necesita justificación, siendo como es inherente a la verdadera existencia de las comunidades políticas; lo que necesita es legitimidad" (2010: 70). Grato y fructífero concepto, el de legitimidad, sobre todo para el politólogo, a quien permite evaluar la capacidad de un poder determinado para obtener obediencia sin necesidad de recurrir a la coacción que supone la amenaza de la fuerza (forma de violencia); concepto, el de legitimidad, en el que M. Weber deposita el fundamento de la dominación, exponiendo sus conocidos tres tipos ideales: carismática, tradicional y legal-racional. Cuya impronta aún se refleja en los actuales sistemas democráticos que, a pesar de todos los instrumentos y estructuras desarrollados, siguen anclados a determinados conflictos.

Si bien, gracias al análisis científico, hay conflictos que se pueden diferenciar y observar, mejor o peor representados en las democracias occidentales, mediante otra institución relativamente moderna, particularmente denostada a pesar de su necesidad en las democracias contemporáneas: los partidos políticos; y también en otros actores políticos y sociales, si pueden integrar y representar los intereses que se planteen, que al contraponerse a otros también pueden ser considerados conflictivos. Aunque de esa forma, articulándose mediante estructuras que disponen de espacio en ámbito público, se consigue que los efectos del enfrentamiento de unos intereses y otros, se templen, amortigüen; al menos eso es lo que parece haberse logrado después de bastantes convocatorias electorales. Pero para entender mejor cómo los conflictos, en las democracias occidentales, se diferencian y acomodan en estructuras partidarias, hay que considerar el proceso de modernización de la sociedad, de acuerdo con lo que S. Rokkan (1921-1979) estudia y denomina cleavages; las divisiones o hendiduras que se producen entre grandes colectivos sociales al estar enfrentados por la defensa de sus percepciones, de sus intereses; escisiones que pueden cristalizar en partidos políticos, y que él mismo fija en cuatro principales:

1) centro/periferia, con la consecuente emergencia de nacionalismos; 2) campo/ciudad, dando lugar a partidos (y movimientos) agrarios (hoy ecologistas) y librecambistas (industrializadores); 3) religión/estado, lo que hace surgir partidos confesionales y laicos; y 4) trabajadores/propietarios, que enfrenta a los partidos en los que desemboca el movimiento obrero (con socialistas, comunistas, socialdemócratas, entre otros) contra los partidos burgueses (de conservadores, liberales, entre otros). Siendo ésta última la principal línea de fractura de los actuales sistemas de partidos; aunque ocasionalmente puede parecer difuminada y en su evolución posterior, con frecuencia, se reconoce sumergida en la dialéctica entre izquierda(s) y derecha(s), de un modo u otro presente en todo sistema político que se estructure en libertad. 
Aunque el hecho de que los conflictos, en el espacio público, consigan diferenciarse y en su caso puedan cristalizar en partidos políticos, o en otras formas (grupos de interés o presión, movimientos sociales y políticos, entre otros), y así amortiguarse en su caso, no impide que esos y otros conflictos sigan embargando, apremiando, a los ciudadanos. Pero sí se pueden considerar nuevas formas, más directas y sutiles, de comprender y afrontar esos y otros conflictos, lo que exigirá un giro paulatino de toda una serie de factores que circundan su inexorable existencia.

\section{Un giro para los conflictos}

Una vez que se produce la superación del trauma que suponen las aludidas dos guerras mundiales, cuyo desenlace trae una nueva forma de confrontación, denominada guerra fría, con el enfrentamiento -casi siempre soterrado- del bloque del Este frente al del Oeste, del comunismo frente al capitalismo, también se inicia un profundo movimiento de contestación, de crítica radical, al orden posbélico establecido. Crítica que surge, con más fuerza a finales de los años sesenta del siglo pasado, desde muy distintos ámbitos, intelectuales, juveniles, a veces orientada por el marxismo pero no sólo, pues el psicoanálisis y otras teorías también le proporcionan material, para dirigirse contra muchas de las instituciones que hasta entonces se consideran casi sagradas; desde la familia al sistema de producción, de las relaciones de pareja a las jerarquías políticas y sociales. Se trata de una heterogénea y vigorosa interrogante puesta sobre las estructuras dominantes que se difunde por tecnologías que empiezan a llegar a amplias capas sociales, en el caso sobre todo la televisión, que también permite una mayor comunicación entre diferentes partes del globo, y que se hace posible con la paz que proporciona la guerra fría, después de algunos años de cierta prosperidad económica. El gran movimiento al que se alude, en general conocido como el origen de los llamados nuevos movimientos sociales ${ }^{17}$, visto en su conjunto y después de muchos años, expresa el descontento, el hastío, el malestar que entonces principalmente siente una juventud que no se considera partícipe de dicho orden, en particular porque no ha vivido los anteriores fracasos, y pretende afrontar el porvenir de otro modo. Aunque con la dinámica que imprime atraviesa toda la población e impregna a la sociedad más activa y, hasta cierto punto, llega a transformar el sistema de relaciones sociales en muchos aspectos, aportando una visión más abierta y plena. Ese movimiento heterogéneo que no sólo se limita al mayo parisiense de 1968, sí que tiene en él un exponente claro y hasta cierto punto radical de los cambios que se van a ir demandando y poco a poco producien-

${ }^{17}$ Sobre los que existe una muy amplia bibliografía, entre otros muchos, pueden verse: D. della Porta y M. Diani (2011), Los Movimientos Sociales, Ed. Complutense-CIS, Madrid, y P. Román y J. Ferri (eds.) (2002), Los movimientos sociales. Conciencia y acción de una sociedad politizada, Ed. Consejo de la Juventud de España, Madrid. 
do, aunque no siempre en la dirección que se reclama; alcanzando sus efectos hasta nuestros días. Sumando todos los elementos que trastoca el proceso de cambio abierto, indirectamente también consigue propiciar una visión nueva del conflicto, más acorde y asumible, al enfocarlo y darle respuesta desde nuevas posiciones; aunque aquí sólo se pueden ofrecer algunos de los rasgos, más o menos significativos, que inciden en el objeto de nuestro interés, de todo el amplio espectro que el movimiento abarca en su conjunto.

En el ámbito más directo de la concepción de la política, entonces, finales de los años sesenta, se pasa a entender que ésta también se encuentra en el espacio individual: lo personal es político, es el resumen que se suele hacer de una transformación que hará que la política también se centre en las personas, el self también cuenta; alejándose en cierto modo de las instituciones oficiales, del establishment, buscando una profundización y una ampliación del derecho a participar de todos y cada uno. Lo que también puede arrastrar, pasados los años, a un individualismo extremo, cuyas indeseadas consecuencias entonces no pueden ser observadas. De ese modo, en la época en que se pone de manifiesto, se produce la politización de la vida cotidiana, pues toda una nueva y amplia serie de sujetos se incorporarán en primera persona a la esfera de la política, transformando el contenido de la misma, tanto en los temas que han de examinarse como en las fronteras que han de delimitar lo público y lo privado; lo que también exige una coherencia entre los valores políticos individuales y su comportamiento social. Así se entiende la nueva reivindicación feminista, la demanda ecologista, el pacifismo, la exigencia de derechos sexuales para todas las orientaciones, entre otras muchas demandas que surgen en el momento. Toda la transformación que propician, aquí sólo citada, también lleva a considerar que los conflictos lo son entre las personas en las distintas relaciones que establecen, y no sólo entre las grandes dimensiones aludidas, entre los estados, las naciones, entre las ideologías; al margen de lo que puedan establecer y determinar las instituciones citadas, $\mathrm{u}$ otras de distinto orden. Y así se podrán ir articulando alternativas que sin contradecir, en principio, lo que puedan dictar las normas, sí permiten encontrar arreglos directamente entre las partes. Junto a todo ello ha de sumarse, no puede dejar de citarse por la correspondencia existente, el movimiento por los derechos civiles que, entre otros, lidera Martin Luther King (1929-1968) en Estados Unidos, que consigue que los derechos, en particular los derechos políticos, también alcancen a los ciudadanos negros ${ }^{18} \mathrm{y}$ de otras minorías, de manera real, y no sólo nominalmente, al margen de su origen étnico, al margen de que cumplan los requisitos del supuesto modelo americano $\left(W A S P^{19}\right)$, en un proceso de extensión que también alcanzará y transformará otras relaciones. Por lo que es allí, en Estados

${ }^{18}$ Una excelente versión de la situación y la lucha reivindicativa se puede ver en, Roca, J.M. (2008), Nación negra, poder negro, Ed. La linterna sorda, Madrid.

${ }^{19}$ Acrónimo en inglés de blanco, anglosajón y protestante; White, Anglo-Saxon and Protestant 
Unidos, donde antes surgen fórmulas alternativas para la resolución de conflictos, A.D.R. en sus conocidas siglas en inglés, Alternative Dispute Resolution ${ }^{20}$, que es el nombre dado al proceso en que las partes en una controversia intentan llegar a un acuerdo (o arreglar su disputa) sin tener que acudir a los tribunales de justicia, en su definición más simple; y para llevarlo a cabo, con frecuencia, se acude a la figura de un mediador en principio imparcial y profesional. Entre otras razones porque las instituciones, y los tribunales de justicia en concreto, se consideran alejados, distantes, caros, para la vida cotidiana de las personas comunes; la gente corriente que así aparece y toma la escena, procurándose fórmulas alternativas para deshacer sus conflictos cotidianos, buscando acuerdos que puedan satisfacer a las partes enfrentadas mejor que lo harían, en muchos casos, sentencias dictadas sin conocer las verdaderas demandas e intereses de las partes. Y así, al mismo tiempo, el conflicto también se asimila y pasa a ser considerado como una parte consustancial de la vida social; y puede dejar de ser visto como el gran problema trágico, ineludible y pesaroso, que en parte es herencia de la tradición mitológica y bíblica, proveniente de la visión que nos heredan Atenas y Jerusalén.

Al mismo tiempo, en la época referida, también se propaga una mentalidad antibelicista, lo que resulta lógico después de las dos guerras mundiales y de la nefasta forma en que concluye la última, con las bombas atómicas de Hiroshima y Nagasaki; pero que aún persevera, con la guerra de Vietnam ante la que se alzará una gran contestación seguida por millones de jóvenes, universitarios, intelectuales, por primera vez en el mundo, que forma parte del poderoso movimiento de protesta que entonces atraviesa el globo. En lo que sin duda también influye el pacifismo como nueva forma de entender las relaciones de todo tipo; hasta cierto punto siguiendo la estela que Mahatma ${ }^{21}$ Gandhi (1869- 1948) consigue dejar después de lograr la independencia de su patria, la India, a través de una nueva forma de combatir al invasor conocida en Occidente como 'resistencia pacífica' que también conlleva 'desobediencia civil'. De la que aprenderán todos los que quieren contestar contra un orden, una determinada armonía social, que parece impostada, que sólo satisface a los que están arriba de la pirámide, los menos que consiguen imponer una jerarquía y unas relaciones que perjudican a los más. En la misma línea, a finales de los años cincuenta del siglo pasado, pretendiendo dar vigor a los estudios sobre la paz, J. Galtung (1930) junto a otros investigadores, funda en Oslo el Instituto de Investigación para la Paz, probablemente la primera entidad que va a empezar a promo-

${ }^{20}$ No se repetirán aquí las distintas fórmulas que comprende, habitualmente, la resolución alternativa de conflictos, como son la negociación, la mediación, el arbitraje y, en ocasiones también se considera, la conciliación, cuando el mediador juega un papel más activo. Entre otras razones porque pueden encontrarse en abundantes documentos y páginas 'colgadas' en la red, como, por ejemplo, http://www.opm.gov/er/adrguide/section1-a.asp ,

${ }^{21}$ Literalmente el Magnánimo, en alusión a sus dotes de profeta y de santo, apelativo que le impone su propio pueblo. 
cionar una nueva cultura de paz, consistente, en apretado resumen, en el conjunto de actitudes, comportamientos y valores que rechazan la violencia y pretenden prevenir los conflictos analizando sus causas y utilizando el diálogo para superar los problemas $^{22}$; además Galtung, en particular, ha contribuido de manera muy importante a investigar sobre la violencia y sus diferentes formas (violencia estructural, cultural y directa), así como en la construcción, el establecimiento y el mantenimiento de la paz, a través de procesos de mediación que ha estudiado y en los que ha participado, con aportaciones que son seguidas en todo el mundo ${ }^{23}$.

En el ámbito del pensamiento en principio limitado al ámbito sólo académico, entre otros, destaca L. Coser (1913-2003) quien hace una importante aportación, fundamentalmente, en su libro, de 1956, Las funciones del conflicto social, al considerar que este puede ser beneficioso por los efectos integradores que supone para un grupo determinado al cohesionarlo, dándole plenitud y firmeza, hasta el punto que dicho grupo podría no existir si no fuera por el conflicto al que hace frente. El intento de integración a partir de una situación de desigualdad social provoca conflicto, pero dicho conflicto es precisamente el factor del cambio social. Consideraciones que suponen un giro muy importante a todo lo que hasta el momento se venía manteniendo, particularmente si a ello se suman todas las demás aportaciones citadas que, desde otros campos, reman en la misma dirección. En adelante, otros sociólogos, como R. Dahrendorf ${ }^{24}$ (1929-2009) también han continuado y expandido el camino de entender los conflictos con más efectos positivos, en definitiva, que negativos. Y con la llamada teoría de juegos y, en concreto, con el dilema del prisionero se viene a comprobar la idea de que los conflictos son globalmente positivos cuando se utilizan procedimientos cooperativos (Axelrod, R., 1996) para afrontarlos, métodos que permiten a las partes seguir manteniendo una buena relación en el futuro.

En el mismo sentido, pero con una orientación muy práctica, desde la Universidad de Harvard, R. Fisher y W. Ury, con la aportación posterior de B. Patton, algunos años más tarde, en 1981, publican un libro, Getting to Yes (traducido al castellano como: Sí, de acuerdo!) que va a cambiar muchas de las posiciones iniciales, al considerar que, si se utilizan las formas adecuadas para gestionar los conflictos que son las que utilizan los mejores negociadores, a los que ellos han investigado, las partes inicialmente enfrentadas pueden conseguir sus objetivos, en concreto, si siguen la sistemática que también ellos elaboran. La investigación da lugar a una

${ }^{22}$ Se encuentra recogida en la resolución 52/243 aprobada por la Asamblea General de Naciones Unidas, el 6 de octubre de 1999.

${ }^{23}$ Entre sus numerosas obras referidas a las materias aquí tratadas puede citarse, quizá porque puede compendiar mucho de su pensamiento, en castellano: (2004), Trascender y Transformar. Una introducción al trabajo de conflictos, Transcend y Ed. Quimera, México.

${ }^{24}$ Entre sus obras con esa temática deben citarse, Las clases sociales y su conflicto en la sociedad industrial (1979), Ediciones Rialp, Madrid; y El conflicto social moderno: (encargo sobre plástica de libertad (1994), Mondadori, Madrid. 
nueva forma de afrontar las negociaciones, elaborándose programas que permiten aprender las formulas más adecuadas para desarrollar una negociación exitosa para ambas partes, que es conocida como el método Harvard, con aplicaciones en campos muy distintos, comercial, laboral, familiar, organizacional, que también debe atravesar lo personal, y que desde luego, tiene una aplicación muy directa en el ámbito político.

Toda una serie de cambios, como los aludidos y otros, en ocasiones, muy profundos, y en ámbitos muy diversos pero con una tácita orientación común, que también puede tener su reflejo en cómo se han de concebir las relaciones políticas, transformando el sentido que ha de darse incluso a aspectos tan sensibles como es la concepción de la democracia, pues, desde los años ochenta, hay consideraciones que también se aproximan a la visión que propician las transformaciones indicadas, al proponerse la democracia deliberativa; ya que votar sin discutir, sin observar las razones a favor y en contra, de unos y otros, en el fondo no es tan democrático, como se puede resumir en una primera aproximación el contenido de la nueva propuesta. Con ella se trata de completar la noción de democracia representativa, trasladando al ámbito político la concreción del ideal participativo (recuérdese los regalos de los dioses, en el relato de Platón), mediante la deliberación, y no sólo sumando los votos, o imponiendo las decisiones. De hecho, también en las políticas públicas, lo que siempre parece tener un fundamento más realista que la teoría, se han visto aplicaciones ${ }^{25}$ en ese sentido, entendiendo que "la clave de todo está en entender la deliberación como un intercambio dialogado de argumentos para producir soluciones óptimas para el conjunto de la comunidad” (Brugué, Q. y Parés, M. 2011: 4). Lo que supone incorporar a las partes en conflicto para que dialoguen sosegada y razonablemente, aspecto que llevará a cabo todo proceso de mediación que se precie. Con la que, sin duda, tiene similitudes evidentes, pues siguiendo a nuestros autores, en cita de Gutmann y Thomson (2004), se sostiene que para poder hablar realmente de deliberación deben satisfacerse cinco condiciones: Primero, las decisiones deben ser razonadas y deben responder a un intercambio de argumentos a partir del respeto mutuo. Segundo, el intercambio debe ser comprensible y accesible a los ciudadanos. Tercero, las decisiones derivadas de la deliberación deben ser vinculantes. Cuarto, el proceso de deliberación debe ser dinámico y por lo tanto estar siempre abierto. Y, quinto, la deliberación debe regirse por la economía moral del desacuerdo, minimizando las diferencias y priorizando los elementos de acuerdo por encima de los de desacuerdo. En definitiva se trata de elevar la condición de ciudadanía, haciendo que esos ciudadanos puedan hacer algo más que sumar intereses y atenerse a la mayoría resultante, demostrando que son (somos) capaces de

${ }^{25}$ Ver, Brugué, Q. y Parés M. (2011): Frente al conflicto deliberación: el caso de la Mesa de la Montaña de Aragón. GIGAPP Estudios/Working Papers. Grupo de Investigación en Gobierno, Administración y Políticas Públicas. Instituto Universitario de Investigación Ortega y Gasset. Madrid. No. WP-2011-07. 23 pp. 
convertirse en un pueblo con aspiraciones compartidas y propósitos comunes en cuestiones de justicia. Y para convencerse de ello es preciso ir a las bases, como nos recuerda A. Cortina (2004), sobre todo cuando en ellas hay experiencia de deliberación: a los comités y comisiones de ética en las distintas esferas de la vida social, cuando tratan de encontrar con argumentos lo mejor para sus beneficiarios; a los hospitales y centros de salud, a las universidades y centros escolares, a la acción de los jueces, a los comités de las empresas, a las comisiones de medios de comunicación, a los ayuntamientos, a las asociaciones profesionales; a todos estos lugares cuando se toman en serio las metas por las que existen, y no las traicionan contentándose con la mera suma de sus intereses. Potenciar la deliberación en todos ellos permite hacerla creíble y mostrar con hechos que ése debería ser el procedimiento habitual en la vida cotidiana para decidir con justicia en cuestiones vitales que a todos afectan. Que debería convertirse en costumbre el diálogo de quienes están dispuestos a argumentar y también a dejarse convencer con argumentos, y lo otro, el recuento de votos sin auténtico diálogo, debería ser lo excepcional, no digamos ya la imposición. Precisamente todo lo que el mediador, y en especial el mediador político, ha de conseguir que se ponga en claro en el proceso que debe conducir, con aplicación inmediata en los ámbitos que se señalan.

\section{El conflicto como oportunidad y la mediación para encontrarla. Procesos de paz.}

Con los cambios referidos se van a ir transformando algunas de las ideas más asentadas sobre la significación y el alcance del conflicto que, en general, pasará de considerarse como algo negativo a entenderlo como una oportunidad que, entre otras ventajas, puede permitir cambiar las relaciones de poder (el propósito de toda alternativa política). Y así también se cambia la forma de afrontarlo, entendiendo que es mejor negociar que enfrentarse a la otra parte; y para negociar, casi siempre, lo mejor será recurrir a un tercero, hasta cierto punto imparcial, para que establezca una mediación entre las partes en disputa, pero que ya supone una forma más positiva de encararlo.

Pues el propósito de la mediación no es determinar quién está en lo correcto y quién está equivocado, sino ir a la fuente de la disputa y buscar una salida digna para ambos. El mediador escucha a cada una de las partes, trata de entender cuáles son sus reales intereses y necesidades, y ayuda para que lleguen a un arreglo que les funcione. El mediador, en términos generales, solamente asiste a las partes, pues la mediación al fin es una 'negociación asistida' como ha expresado W. Ury (en Diez, F., y Tapia, G., 1999: 15). Y de acuerdo con lo que se indica, también Fisher y Ury, entienden que "el conflicto no está en la realidad objetiva sino en la mente de las personas. La verdad es sólo un argumento más para tratar las diferencias"; y por eso postulan el método de "separar las personas del problema" y consideran que para orientarse en el "laberinto problemático de las personas, es útil pensar en términos de tres categorías: percepción, emoción y comunicación” (1994: 26). Ponen énfasis 
en los elementos subjetivos a la hora de observar el conflicto; para buscar la salida, el arreglo, solicitan que existan criterios objetivos que le den legitimidad.

El llamado método Harvard, que los citados autores del Sí, de acuerdo ponen en marcha, fundamentalmente, considera que se deben seguir siete elementos (Comunicación, Relación, Intereses, Opciones, Criterios, Alternativas y Compromiso) que son los que debe conducir todo proceso de negociación, observando las pautas que en cada elemento se consideran; desde que se trata de relaciones entre personas en las que conviene distanciarse de los problemas (conflictos) que están sobre la mesa, a recomendar que se deben desmontar las posiciones iniciales para permitir que florezcan los verdaderos intereses de las partes (para lo que se ofrecen técnicas eficaces), considerando también cual es la 'mejor alternativa a un acuerdo negociado' (MAAN), y otras recomendaciones que pueden ofrecer resultados óptimos, lo que supone que la contraparte también debe ganar, entre otras razones, porque la relación se ha de mantener, pues en el futuro también puede precisarse a esa contraparte. Se trata de un modelo muy elaborado, práctico y claro, del que sólo se ofrece un apunte, que se ha verificado en ámbitos muy diferentes, aunque no es la panacea, lo que además no es posible.

Junto al método Harvard, que tan sólo pretende arreglar el problema, el conflicto planteado entre las partes, de la manera más clara y directa posible, está el modelo llamado transformativo, orientado a la comunicación y a las relaciones interpersonales de las partes; sus primeros iniciadores Busch y Folger (1996) proponen diferenciarlo del anterior modelo al que incluyen dentro de lo que denominan historia de satisfacción, al darle un enfoque terapéutico en un marco que llaman la historia de la transformación. Para ellos el objetivo no es el acuerdo sino el desarrollo del potencial de cambio de las personas al descubrir sus propias habilidades, ya que focalizan en las relaciones humanas su desarrollo, con la intención de fomentar el crecimiento moral, destacando la capacidad de este procedimiento para promover la revalorización y el reconocimiento de cada persona. Entre sus seguidores, con una marcada orientación hacia los procesos de paz, debe citarse a J.P. Lederach ${ }^{26}$. También se debe mencionar el modelo circular narrativo, cuya principal exponente sigue siendo S. $\mathrm{Cobb}^{27}$, quien focaliza todo su trabajo en las narraciones de la gente; este modelo también tiene como objetivo llegar a un acuerdo pero con el énfasis puesto en la comunicación y en la interacción de las partes. El presupuesto del que parte es que para poder llegar a un acuerdo las personas necesitan transformar las

${ }^{26}$ Ver, entre otros, de dicho autor, (1998), Construyendo la paz. Reconciliación sostenible en sociedades divididas, Guernika Gogoratuz, Bilbao; y (2000), El abecé de la paz y los conflictos: Educación para la paz. Libros de la Catarata, Madrid.

${ }^{27}$ Cuya producción bibliográfica es escasa, pudiendo citarse (1995), Hacia un nuevo discurso para la mediación. Una crítica sobre la neutralidad. Material bibliográfico del curso "Negociación y resolución de conflictos". Santa Bárbara: Universidad de California. 
historias conflictivas con las que llegan a la mediación en otras -narraciones- donde queden mejor posicionadas.

Las diferentes técnicas y métodos de negociación y de mediación son consustanciales, o debieran serlo, a la política; y si ésta es una actividad especialmente pertrechada para manejar el conflicto en el seno de las sociedades, como se ha señalado atrás, es obvio que su relación con las claves de la negociación y la mediación tiene que ser estrecha. La necesidad de arbitrar, gracias a la toma de decisiones, los diferentes intereses en conflicto, es una de las señas de identidad capital de la política, así como abordar el conflicto no como algo negativo y de lo que hay que huir, sino como una oportunidad para mejorar la convivencia. Es la oportunidad que permite que la -auténtica- política muestre su capacidad para ser el espacio de encuentro desde el que se delibera sobre las salidas posibles a los inexorables conflictos. Si bien hay quien puede pensar que así se está provocando cierta paradoja democrática (Mouffe, Ch., 2012), pues el empeño en negar el conflicto como algo esencial de toda política democrática, buscando el consenso y promoviendo una unanimidad social suave, lejos de ser un signo de progreso, es un grave error que pone en peligro las instituciones democráticas. En muchos países además, se esgrime, ese ‘consenso centrista' está propiciando el auge de partidos de la derecha populista, que se presentan como las únicas fuerzas 'contrarias al sistema', aspirando así a ocupar el espacio de la crítica abandonado por la izquierda; nuevas paradojas, cuando parecía que el círculo se cerraba.

En todo caso, las aplicaciones que toda esa serie de cambios ha tenido en el pensamiento y en los hechos son muchas, en el campo de la Ciencia política y de las Relaciones internacionales aplicadas, en particular, ha conseguido conformar un nuevo campo, en general denominado, Resolución de $\operatorname{conflictos}^{28}$; cuyo desarrollo se ha podido ir comprobando en algunos de los conflictos más importantes y conocidos del mundo contemporáneo en los que se han realizado procesos de paz ${ }^{29}$, como ha sido la superación del apartheid en Suráfrica, de 1989 a 1994, entre los primeros en los que se pusieron en marcha claves de mediación. Anteriormente, ya se habían sucedido procesos de paz, casi siempre, con mediaciones profesionales; en muchos casos, de Naciones Unidas y en algunos otros, con agencias especializa-

${ }^{28}$ Entre otros muchos, puede verse, Ramsbotham, O., Woodhouse, T., y Mial, H., (2011), Resolución de conflictos. La prevención, gestión y transformación de conflictos letales, Institut Català Internacional per la Pau y Edicions Bellaterra, Barcelona. También de gran interés, Harris, P., Reilly, B., y Zovatto, D. (eds.) (2001), Democracia y Conflictos profundamente arraigados: Opciones para la negociación, International Institute for Democracy and Electoral (IDEA), Stockholm, Sweden.

${ }^{29}$ Puede verse un excelente resumen de dichos procesos, en Vicenc Fisas (2010), Procesos de paz comparados, Quaderns de Construcció de Pau, Agència Catalana de Cooperació al Desenvolupament, Barcelona. Del mismo autor también debe ser vistos, Anuario sobre la paz (2012),Ed. Icaria, Barcelona, en esta séptima edición se observan los conflictos donde hay negociaciones para llegar a acuerdos de paz. 
das, como es IGAD ${ }^{30}$, incluso organismos independientes que es como se define el Centro para el Diálogo Humanitario $(\mathrm{CDH})^{31}$, y en ocasiones también con la participación de terceros países, acordados por las partes en litigio. Tratándose de procesos de compleja resolución y de larga duración, conviene ofrecer algunos datos, como que se han contabilizado un mínimo de 4 años para poner fin a los procesos de paz en El Salvador, entre 1984 y 1994; en Guatemala, entre 1985 y 1996; en Irlanda del Norte, uno de los procesos más largos, 21 años, entre 1987 y 2008, cuyo aleccionador proceso se ha querido utilizar en el conflicto vasco (acaso con más éxito del que se supone, y donde la intervención del citado CDH también se ha puesto de manifiesto); en Angola, de 1988 a 2002; en Tayikistán, entre 1992 y 1997; en Sierra Leona, de 1994 a 2002; Sur de Sudán, de 1998 a 2005, donde participó la mediación del citado IGAD; en Burundi, de 1998 a 2008; en Indonesia (Aceh) de 2000 a 2005 y en Nepal entre 2002 y 2006; siendo los motivos de fondo para generarse el conflicto, en los casos citados y en síntesis, la democratización del país (en cuatro de ellos), el reparto del poder político (en otros cuatro) y el autogobierno de una parte del territorio (en los tres restantes).

Quizá en lo que más se diferencie la mediación política ${ }^{32}$ dedicada a los procesos de paz es que, con frecuencia, excede la noción convencional de la práctica de la mediación, ya que en muchas ocasiones sigue un modelo basado en el poder de negociación y no en un modelo puro, contenido, de mediador imparcial de conflictos; así, en este tipo de conflictos políticos, se puede hablar de: -mediador facilitador (pues crea las condiciones para que las partes puedan obtener su propia solución a su ritmo), - de mediador formulativo (diseña y presenta algunas soluciones, a veces para expresar preferencias por determinados resultados, y para impulsar el proceso y hacerlo más rápido), -y de mediador de poder (pues al tratarse de una autoridad, como ocurre en ocasiones, aprovecha su capacidad para presionar a las partes hacia un acuerdo). En todo caso, los acuerdos que se pueden lograr tienen un alcance muy diferente, desde acuerdos mínimos (acuerdos para comenzar a hablar, a acuerdos de alto el fuego, de cese de hostilidades) a compromisos más completos (con acuerdos de transición, y acuerdos globales); y todos pueden ser de gran interés pues casi siempre lo que detrás está en juego es la vida para muchas (o aunque fueran pocas) personas.

Un proceso de paz no puede esquivar las distintas fases que cualquier mediación requiere: 1) La fase previa a las conversaciones, que normalmente requiere confi-

\footnotetext{
${ }^{30}$ Ver, http://igad.int y más en concreto, http://igad.int/index.php?option=com_content\&view=article\&id=93\&Itemid=124

${ }^{31}$ Ver, http://www.hdcentre.org/about

${ }^{32}$ Ver, del Hoyo Alonso-Martínez, P. (2010), 'Notas sobre la mediación en conflictos políticos’, en García Villaluenga, L., Tomillo Urbina, J., y Vázquez de Castro, E., Mediación, arbitraje y resolución extrajudicial de conflictos en el siglo XXI, Ed. Reus, Madrid.
} 
dencialidad y evaluación de la voluntad de las partes; 2) Diálogos, que exigen una hábil combinación de diplomacia, conversaciones indirectas y conversaciones directas; 3) el Acuerdo, que requiere capacidades importantes para finalizar los acuerdos, sin dejar abiertos temas de interés, y para diseñar mecanismos apropiados para la implementación; y 4) la Implementación, donde las habilidades para el diálogo continuo, la supervisión y la verificación, han de ser muy consideradas. En cualquier caso, en la fase previa, que requiere un análisis riguroso del conflicto, lo que normalmente no se pone de manifiesto, los conocimientos politológicos serán cruciales y no pueden ser soslayados, pues las partes querrán utilizarlos en su provecho y más en caso de desconocimiento; por eso un buen mediador debe estar más que al día de la cuestión que se disputa, de las causas que la motivaron, de los apoyos que tienen los bandos, de la posición y los intereses de los actores implicados; en resumen, debe contar con un excelente análisis previo de carácter politológico. Ese conocimiento exhaustivo, exigible a un mediador político, permite que la comunicación entre las partes, desde el primer momento, pueda ser fluida; no hay interferencias para explicar cómo son 'las cosas', lo que permite alcanzar con mucha mayor rapidez, la confianza precisa que toda negociación ha de tener para llegar a buen puerto.

Pero no sólo se trata de procesos de paz, de acuerdos internacionales, la mediación tiene aplicación, indudable, a la vida diaria, a la política cotidiana. A las relaciones comerciales, cuando hay disparidad de interpretaciones y no se quiere recurrir a tribunales porque dilatarán el arreglo, si lo alcanza, encareciendo los costes y frustrando las expectativas; a las relaciones familiares, ante los conflictos entre padres e hijos, entre parejas, ámbito muy propicio para la mediación porque, entre otras razones, puede ayudar a cerrar las heridas que las rupturas pueden ocasionar; así como en las relaciones organizacionales y laborales, en los que una buena mediación práctica puede ahorrar tiempo y energías consumidas en frustrantes disputas y combates, con frecuencia, con patronales y sindicatos; puede ayudar también en procesos de integración intercultural, pues la mediación es una excelente técnica para ese propósito, existan o no enfrentamientos entre diferentes colectivos sociales. En fin un amplio abanico que, en definitiva, recorre todos los ámbitos donde hay personas que viven en común, en los que siempre habrá conflictos, como al principio decíamos; aunque ahora, después de haber observado parte de su evolución, quizá se pueden entender de otro modo. 


\section{Referencias bibliográficas}

Arendt, H. (2010), Sobre la violencia, Alianza, Madrid.

Axelrod, R. (1996), La evolución de la cooperación: el dilema del prisionero y la teoría de juegos, Alianza Ed., Madrid.

Brugué, Brugué, Q. y Parés M. (2011): Frente al conflicto deliberación: el caso de la Mesa de la Montaña de Aragón. GIGAPP Estudios/Working Papers. Grupo de Investigación en Gobierno, Administración y Políticas Públicas. Instituto Universitario de Investigación Ortega y Gasset. Madrid. No. WP-2011-07.

Busch, R.A. y Folger, J. (1996), La Promesa de la Mediación. Cómo afrontar el conflicto mediante la revalorización y el reconocimiento, Granica, Barcelona.

Castells, M. 'Presentación’ en Vinyamata, E. (2001): Conflictología. Teoría práctica en Resolución de Conflictos, Ariel, Barcelona.

Cortina, A. (2004), Democracia deliberativa, El País, 24 de agosto.

Coser, L. (1961), Las funciones del conflicto social, Ed. Fondo de Cultura Económica, México, 1961 (Original en 1956: The functions of social conflicts, Free Press, New York)

Dahl, R. (1965): ‘¿Qué es la Ciencia Política? ', en Stephen K. Bailey (comp.), Como se gobierna un país, Compañía General Fabril Editora, S.A., Buenos Aires.

Duverger, M. (197): Instituciones políticas y Derecho Constitucional, Ariel, Barcelona.

Fisher, R.y Ury,W., con Patton, B., (1981), Getting to Yes, traducido como: (1985) Sí, de acuerdo!, Ed. Norma, Bogotá, Colombia.

Giner, S. (1998), 'Teoría del conflicto’, en Giner, S., Lamo de Espinosa, E., y Torres, C. (eds.): Diccionario de Sociología, Alianza, Madrid.

Keane, J. (1996), Reflexiones sobre la violencia, Alianza, Madrid.

Maquiavelo, N. [1970]: El Príncipe, Espasa-Calpe, Madrid.

Mouffe, Ch., (2012), La paradoja democrática. El peligro del consenso en la política contemporánea. Ed. Gedisa, Barcelona.

Platón, [1985]: Protágoras, en Diálogos I, Ed. Gredos, Madrid. También: http://www.acropolis.org.uy/Investiga_y_Comparte/Biblioteca_Virtual/Platon/Pl aton\%20-\%20Protagoras.pdf.

Rokkan, S. (1967), "Cleavages Structures, Party Systems and Voter Alignments: An Introduction”, en, junto a Lipset, S.M., eds., Party Systems and Voter Alignments. Gross-National Perspectives, New York, Free Press.

Sartori, G. (1999): Elementos de teoría política, Alianza, Madrid.

Vallès, J.M. (2000): Ciencia política. Una introducción, Ariel, Barcelona.

Weber, M. [1922] (1944), Economía y sociedad, Fondo de Cultura Económica, México.

Weber, M. [1919] (1992), La ciencia como profesión. La política como profesión, Edición de J. Abellán, Espasa Calpe, Madrid. 